\title{
DEPENDENCIA Y DESARROLLO EN AMÉRICA LATINA DE FERNANDO HENRIQUE CARDOSO Y ENZO FALETTO*
}

\author{
Alberto Mayol Miranda
}

A fines de los años 60 un documento circulaba por las manos de los numerosos cientistas sociales que vivían en Chile. Su influencia fue inmediata, y ya antes de su edición impresa el documento era referencia obligada entre los especialistas. Años después, específicamente treinta años después, en un congreso de la Asociación Internacional de Sociología, el mismo libro fue seleccionado entre los 25 más utilizados por los sociólogos asistentes de todo el mundo, luego de una encuesta que se realizó a todos quienes asistieron, los cuales declararon qué libros eran los que más usaban. Era el único libro en castellano que logró entremeterse en un listado de clásicos. El libro es Dependencia y desarrollo en América Latina y fue escrito por Fernando Henrique Cardoso (brasileño) y Enzo Faletto (chileno). Y naturalmente la pregunta salta a la vista: ¿qué rasgo, qué argumentación transformó ese libro en un clásico?

Las teorías que intentan explicar qué significa y cómo se produce el desarrollo han sido vastas. El sentido común se basa en la primera teoría moderna sobre el tema, cuando Adam Smith escribió La riqueza de las naciones, libro donde explicaba cómo el aumento de la capacidad productiva deriva fundamentalmente de la mejor organización del trabajo, que bajo condiciones de eficiencia supone un mayor desarrollo. Detrás del argumento se mueve un supuesto fundamental: cada sociedad es dueña de su historia, y su capacidad para producir desarrollo parece enmarcarse siempre en un proceso, más o menos eficiente (y por tanto, más o menos veloz), de "crecer progresivamente" desde una situación de subdesarrollo a una de desarrollo. Desde aquí es que asumimos que ciertas naciones "todavía" no "alcanzan" a otros pueblos, "más desarrollados". Cada sociedad correría (según esta visión) con sus propias fuerzas por un carril autónomo, luchando contra sí mismo en la ejecución, aunque en el resultado final haya una comparación con el otro.

La "teoría de la dependencia", de la que el libro de Faletto y Cardoso resulta ser la obra icónica, plantea una mirada completamente diferente a las teorías derivadas de la economía clásica. Las "situaciones de desarrollo" se dan en el marco de relaciones específicas entre el crecimiento interno y la vinculación externa. Estas relaciones son políticas, es decir, el núcleo del orden económico radica en las relaciones políticas (los intereses, las coordinaciones de ellos, la organización orientada a satisfacerlos, los conflictos). Es así como las relaciones de poder dividen las condiciones de desarrollo en sectores diferentes a nivel mundial, otorgando a cada sociedad un condicionamiento que tiende a forzarla en una u otra dirección, empujando hacia mayor desarrollo o subdesarrollo. Las regiones periféricas, subdesarrolladas, explicarán entonces el desarrollo

* Cardoso, F.H., Faletto, E., Dependencia y desarrollo en América Latina, Buenos Aires: Siglo XXI Editores, 1977. 
de las regiones centrales, cuyo crecimiento se fundamenta en una división mundial del trabajo, generándose mayores concentraciones de capital y mejores mercados laborales que en la periferia. Deja así de ser anecdótico dónde uno está parado y, entre otras cosas, señala como absolutamente errática la fórmula (que es la chilena actual) de un modelo exportador de materias primas, pues ese camino establece una relación de fuerte dependencia con los países centrales, lo que directamente significa un muro de contención de cualquier esfuerzo para llegar al desarrollo.

Esta teoría permitió dar un nuevo repertorio conceptual para comprender la realidad de América Latina, pero ha sido además sumamente influyente para entender las determinaciones de otros continentes. Además, ha incidido fuertemente en otras teorías de gran relevancia con posterioridad, como la de Immanuel Wallerstein, cuyo concepto del "sistema-mundo" reconoce una herencia de la teoría de la dependencia.

La vigencia de la obra de Cardoso y Faletto es sorprendente y su importancia en todo el continente es indiscutible tanto en la sociología política como en la económica, virtud indiscutible en tiempos donde se ha frecuentado -en un error de graves consecuencias- la visita diferenciada en ambas dimensiones.

Los autores tomaron caminos distintos años después de escribirla. Cardoso fue presidente de Brasil en plena época de eclosión neoliberal (1995 a 2003) y el tránsito que hay desde el autor de este escrito a la conversión en presidente supuso (o tuvo que suponer) la suspensión (parcial o no) de los contenidos de su teoría. Faletto siguió trabajando en Chile, en la CEPAL, en FLACSO y en la Universidad de Chile, donde ejerció hasta su muerte en el año 2003, realizando docencia sobre América Latina, historia y sociología del arte. 